\title{
Application of radial basis neural network for state estimation of power system networks
}

\author{
J.P. Pandey ${ }^{1 *}$, D. Singh ${ }^{2}$ \\ ${ }^{1 *}$ Department of Electrical Engineering, Kamla Nehru Institute of Technology Sultanpur INDIA \\ ${ }^{2}$ Department of Electrical Engineering, I.T,B.H.U Varanasi. INDIA \\ "Corresponding Author: e-mail: tojppandey@rediffmail.com,
}

\begin{abstract}
An original application of radial basis function (RBF) neural network for power system state estimation is proposed in this paper. The property of massive parallelism of neural networks is employed for this. The application of RBF neural network for state estimation is investigated by testing its applicability on a IEEE 14 bus system. The proposed estimator is compared with conventional Weighted Least Squares (WLS) State Estimator on basis of time, accuracy and robustness. It is observed that the time taken by the proposed estimator is quite low. The proposed estimator is more accurate and robust in case of gross errors and topological errors present in the measurement data.
\end{abstract}

Keywords: Radial Basis Function Neural Networks, State Estimation.

\section{Introduction}

Electric Power System deregulation has transformed state estimation from an important application to a critical one. The system operator has to make equitable, security related, congestion management decisions to curtail or deny power transfer rights in real time. It has to be founded and justified on a precise model of the power system derived from the state estimation process. Moreover fast and accurate state estimation is foundation of locational marginal pricing methodologies for transmission management costing.

The state estimation provides the real time representation of the conditions in a power network. A state estimator is a data processing algorithm, which transforms meter readings and the switch status information into an estimate of the system's state (voltage magnitudes and phase angles at all the nodes). Real and reactive bus power injections, and real and reactive line flows and bus voltage magnitudes are the measurements, which are transmitted to computer control system via telemetry system. These measurements contain random noise due to instrument and phenomenon errors. The state estimation program obtains a best fit for the power system state variables by minimizing these errors. Ideally state estimation should run at the scanning rate of the telemetry system (say at every two seconds). Due to computational limitations, most practical state estimators run every few minutes or when major changes occur.

Most of the state estimation problems are formulated as over determined system of non-linear equations and solved as a weighted least squares problem. The Weighted Least Squares Estimation (WLSE) is by far the most popular approach in industry. The least squares technique is slow and computational requirements are prohibitively large since there is large number of redundant measurement data normally available in form of nodal injection and line flows. To overcome this difficulty, a number of alternatives algorithms including modification and refinements of the basic WLSE have been presented (Horisberger et al, 1976; Garcia et al, 1979). The state of the art in state estimation algorithms is presented in (Wu 1990; Monticelli, 2000). Most of the practical implementation of state estimation in electric power systems is based on the Gauss-Newton methods. The state estimates, i.e., the voltage magnitudes and the bus voltage angles are solved through an iterative procedure in least squares sense. 
The slowness of the state estimators due to computational requirements has been a major drawback of the present methods of state estimation employed. The conventional state estimation is based on algorithmic method of solving a large number of nonlinear equations based on network line flows and /or bus injections and network constraints similar to power flow problem.

The present work proposes entirely different paradigm of state estimation problem. In this paper state estimation is addressed as a pattern recognition problem and solved using learning approach. The learning based methods have found wide applications in some EMS applications such as load forecasting, Topology Processing, Optimal unit commitment, Load Flows etc (Singh et al, 2001). In this paper an original application of radial basis function neural network for state estimation is proposed. The property of massive parallelism of neural network is employed for faster state estimation. The proposed estimator is studied for various cases to show its utility for state estimation in terms of accuracy and time requirements.

\section{WLS State Estimator}

Most state estimation programs in practical use are formulated as over determined systems of nonlinear equations and solved as WLSE problem.

Consider the nonlinear measurement model

$$
z_{j}=h_{j}(x)+e_{j}
$$

where $z_{j}$ is the $j^{\text {th }}$ measurement, $x$ is the true state vector, $h_{j}(x)$ is a nonlinear scalar function relating the $j^{\text {th }}$ measurements to states, and $e_{j}$ is the measurement error, which is assumed to have zero mean and variance $\sigma_{j}^{2}$. There are $m$ measurements and $n$ state variables, $n<m$.

The WLS state estimation can be formulated mathematically as an optimization problem with a quadratic objective function and with equality and inequality constraints,

$$
\text { minimize } J(x)=\frac{1}{2} \sum_{j=1}^{m}\left(z_{j}-h_{j}(x)\right) / \sigma_{j}^{2}
$$

subject to

$$
\begin{array}{cc}
g_{i}(x)=0 ; & i=1, n_{g} \\
c_{i}(x) \leq 0 ; & i=1, n_{c}
\end{array}
$$

Equation (1) is an objective function, and $g_{i}(x)$ and $c_{i}(x)$ are the functions representing power flow quantities.

\section{Radial Basis Function Neural Network}

The RBF model consists of two layers namely, a hidden layer consisting of transfer function and a linear output layer. A radial basis neuron receives the vector distance between its weight vector (cluster center) ' $W$ ' and the input vector divided by the spread constant factor unlike sum of product of the inputs and respective synaptic weights as in case of feed forward network.

The RBF unit or transfer function is similar to Gaussian density function, which is defined by center position and spread. The output of the RBF unit is given by

$$
o_{i}=\exp -\left(\sum_{j=1}^{r} \frac{\left(x_{j p}-W_{i j}\right)^{2}}{\sigma}\right)
$$

where

$$
\begin{aligned}
& W_{i j}=\text { Center of the } \mathrm{i}^{\text {th }} \mathrm{RBF} \text { unit for input variable } \mathrm{j} \\
& \sigma=\text { Spread of the RBF unit } \\
& x=\mathrm{j}^{\text {th }} \text { variable of the input pattern }
\end{aligned}
$$

The RBF neural network generalizes on the basis of pattern matching. The different patterns are stored in a network in form of cluster centers of the neurons of the hidden units. The number of neuron determines the number of cluster centers that are stored in the network. If the number of neurons are as large as number of training patterns, permissible maximum number of neurons, all the input patterns will be recognized as separate cluster center, thus it acts like a memory. In case the number of neurons is less than the training patterns, the network will group the similar inputs patterns a single cluster. Thus it will act like a generalizer. The response of particular hidden layer node is maximum (i.e. 1) when the incoming pattern matches the cluster center of the neuron perfectly and the response decays monotonically as the input patterns mismatches the cluster center; the rate of decay can be small or large depending on the value of the spread. Neurons with large spread will generalize more, as it will be giving same responses 
(closer to 1) even for the wide variation in the input pattern and the cluster centers whereas a small spread will reduce the generalization property and work as a memory. Therefore, spread is an important parameter and depends on the nature of input pattern space.

The output linear layer simply acts as an optimal combiner of the hidden layer neuron responses. The weights ' $w$ ' for this layer are found by multiple linear regression technique. The output of the linear layer is given by

$$
y_{m p}=\sum_{i=1}^{N} w_{m i} o_{i}+b_{i}
$$

where,

$$
\begin{aligned}
& N=\text { number of hidden layer nodes (RBF units) } \\
& y_{m p}=\text { output value of the } \mathrm{m}^{\text {th }} \text { node in the output layer } \\
& \quad \text { for the } \mathrm{i}^{\text {th }} \text { incomming pattern } \\
& b_{i}=\text { biasing strength of the } \mathrm{m}^{\text {th }} \text { output node } \\
& o_{i}=\mathrm{i}^{\text {th }} \text { input to the linear layer. } \\
& \mathrm{w}_{\text {mi }}=\text { weight between } \mathrm{i}^{\text {th }} \text { RBF unit and } \mathrm{m}^{\text {th }} \text { output node }
\end{aligned}
$$

The values of the different parameters of the RBF networks are determined during training. These parameters are spread, cluster centers, and weights and biases of the linear layer. The number of neurons for the network and spread is determined through experimentation with a large number of combinations of spread and number of neuron. The best combination is one which produces minimum Sum Squared Error (SSE) on the testing data.

The optimal set of parameters is determined through following procedure. Initially start training with two neurons. The number of cluster centers is the same as number of neurons. The number of neurons is increased gradually till the SSE is reduced to required goal on the training data for a predefined spread. This process is repeated for different number of neurons and spread constants, and finally the one giving the lowest error on the testing data is taken as final architecture.

\section{Design of Neural Network State Estimator}

The radial basis function neural network state estimator is designed and tested for IEEE 14 bus test system (Wallach, 1986). The line flows and bus injection patterns were generated around the base case using Newton-Raphson power flow. The patterns were randomly generated taking random perturbations of $\pm 25 \%$ around the base case. The patterns included data for intact system and various single line outage cases. The power flow patterns were first divided into testing and training patterns. The measurement set containing 28 real and reactive bus injections, 80 real and reactive line flows and 20 line switch status were taken. In all 2000 patterns were generated around the base case out of which 1700 patterns were taken as training patterns and 300 as testing patterns. The radial basis function network was designed using MATLAB Neural Network tool box (Demuth et al, 1992). The network parameters were selected in the sum squared error range (for training data) of 3.00 to 0.5 in the steps of 0.5 and the spread range of 5.00 to 0.2 in steps of 0.2 . The range was decided by making trail and error guesses. The exhaustive search for the best network in the above ranges was made. The network was selected on the basis of sum squared error on the testing data set in the said range of sum squared error and spread. The RBF network which had sum squared error of 0.5 on the training data and spread of 4.6 had the minimum error on the testing data (0.000233). The network had 19 hidden layer RBF units. This network was selected as state estimator for further investigations

\section{Test Result and Discussions}

The performance of the proposed estimator is compared with a conventional WLS state estimator. The performance comparison is made for following test cases.

Case 1: All the measurements are correct (no gross errors).

Case 2: Gross errors in the measurement data.

Case 3: Topological errors in the measurement data.

Gaussian noise of $2 \%$ and $4 \%$ was introduced in the actual bus power measurements (real and reactive) and line measurements (real and reactive) respectively. Tables 1 and 2 shows the estimated voltage magnitudes (V) and bus angle for such a case where no gross errors were present. The Absolute Error, Mean Average Error (MAE) and the Maximum Error (Max.) is also compared for conventional WLS (indicated as Con.) and RBF neural network (indicated as ANN) estimator in these tables. It is observed that the accuracy of the conventional (WLS) method was slightly superior when compared to the proposed method for test case 1. However, estimated states by the proposed method were quite accurate for practical purposes. 
Table 1. Voltage estimates for case 1

\begin{tabular}{|l|l|l|l|l|l|}
\hline $\begin{array}{l}\text { Bus } \\
\text { No. }\end{array}$ & $\begin{array}{l}\mathrm{V} \\
\text { (Act.) }\end{array}$ & $\begin{array}{l}\mathrm{V} \\
\text { (Con.) }\end{array}$ & $\begin{array}{l}\mathrm{V} \\
(\mathrm{ANN})\end{array}$ & $\begin{array}{l}\text { Abs Error } \\
\text { (Con.) }\end{array}$ & $\begin{array}{l}\text { Abs Error } \\
(\mathrm{ANN})\end{array}$ \\
\hline 1 & 1.06 & 1.06 & 1.06 & 0 & 0 \\
\hline 2 & 1.045 & 1.0454 & 1.0456 & 0.0004 & 0.0006 \\
\hline 3 & 1.01 & 1.0104 & 1.0103 & 0.0004 & 0.0003 \\
\hline 4 & 1.014 & 1.0143 & 1.0152 & 0.0003 & 0.0012 \\
\hline 5 & 1.0168 & 1.0171 & 1.0178 & 0.0003 & 0.001 \\
\hline 6 & 1.07 & 1.0704 & 1.0701 & 0.0004 & $1 \mathrm{E}-04$ \\
\hline 7 & 1.0589 & 1.0589 & 1.0627 & 00000 & 0.0038 \\
\hline 8 & 1.09 & 1.0894 & 1.0915 & 0.0006 & 0.0015 \\
\hline 9 & 1.052 & 1.0518 & 1.0549 & 0.0002 & 0.0029 \\
\hline 10 & 1.0477 & 1.0478 & 1.0501 & 0.0000 & 0.0024 \\
\hline 11 & 1.0552 & 1.0557 & 1.0573 & 0.0005 & 0.0021 \\
\hline 12 & 1.0551 & 1.0556 & 1.0569 & 0.0005 & 0.0018 \\
\hline 13 & 1.0493 & 1.0495 & 1.0511 & 0.0002 & 0.0018 \\
\hline 14 & 1.0311 & 1.029 & 1.0351 & 0.0021 & 0.004 \\
\hline MAE & & & & 0.000429 & 0.001679 \\
\hline Max. & & & & 0.0021 & 0.004 \\
\hline
\end{tabular}

Table 2. Bus angle estimates for case 1

\begin{tabular}{|c|c|c|c|c|c|}
\hline $\begin{array}{c}\text { Bus } \\
\text { No. }\end{array}$ & $\begin{array}{c}\text { Angle } \\
\text { (Act.) }\end{array}$ & $\begin{array}{c}\text { Angle } \\
\text { (Con.) }\end{array}$ & $\begin{array}{c}\text { Angle } \\
\text { (ANN) }\end{array}$ & $\begin{array}{c}\text { Abs Error } \\
\text { (Con.) }\end{array}$ & $\begin{array}{c}\text { Abs Error } \\
\text { (ANN) }\end{array}$ \\
\hline 1 & 0 & 0 & 0 & 0 & 0 \\
\hline 2 & -0.0864 & -0.0855 & -0.0853 & 0.0009 & 0.0011 \\
\hline 3 & -0.2188 & -0.2174 & -0.2169 & 0.0014 & 0.0019 \\
\hline 4 & -0.1789 & -0.1774 & -0.1774 & 0.0015 & 0.0015 \\
\hline 5 & -0.1522 & -0.1508 & -0.1508 & 0.0014 & 0.0014 \\
\hline 6 & -0.2467 & -0.2452 & -0.2461 & 0.0015 & 0.0006 \\
\hline 7 & -0.2319 & -0.2304 & -0.2308 & 0.0015 & 0.0011 \\
\hline 8 & -0.2319 & -0.2303 & -0.2308 & 0.0016 & 0.0011 \\
\hline 9 & -0.2594 & -0.2581 & -0.2599 & 0.0013 & 0.0005 \\
\hline 10 & -0.262 & -0.2605 & -0.2625 & 0.0015 & 0.0005 \\
\hline 11 & -0.2562 & -0.2547 & -0.2557 & 0.0015 & 0.0005 \\
\hline 12 & -0.2607 & -0.2593 & -0.2598 & 0.0014 & 0.0009 \\
\hline 13 & -0.2629 & -0.2613 & -0.2616 & 0.0016 & 0.0013 \\
\hline 14 & -0.2802 & -0.2796 & -0.278 & 0.0006 & 0.0022 \\
\hline MAE & & & & 0.001264 & 0.001043 \\
\hline Max & & & & 0.0016 & 0.0022 \\
\hline
\end{tabular}

Tables 3 and 4 show the estimates for (V) and bus angle for test case 2. The gross errors were introduced randomly in four measurements, one each in real power injection, reactive power injection, real power line flows and reactive power line flow measurements. These gross errors are indicated in tables 5-8. The measurements given in the brackets are the actual measurements which were replaced by gross errors. The gross errors were introduced in real power on bus 3 (Table 5), reactive power on bus 2 (Table 6), real power flow in line 5-1 (Table 7) and reactive power flow in line 7-8 (Table 8). It is observed from tables 3 and 4 that the proposed estimator (ANN) outperformed the conventional WLS estimator both on account of MAE (as $0.011464 \angle 0.0146$ for $\mathrm{V}$, and $0.020929 \angle 0.036957$ for angles) and maximum errors (as $0.0501 \angle 0.1128$ for $\mathrm{V}$ and $0.0686 \angle 0.129$ for angles). The Radial Basis Function neural network state estimator was robust when compared with WLSE state estimator for the test case 2. This shows that the gross errors present in the measurement data can deteriorate the performance of the conventional state estimator and have to be removed or reweighed and are to be re-estimated by going through state re-estimation. However, the 
proposed state estimator is robust in such cases. The bad data can easily be detected in case of proposed method, as there is no data smearing possible unlike conventional state estimation.

Table 3. Voltage estimates for case 2

\begin{tabular}{|l|l|l|l|l|l|}
\hline $\begin{array}{l}\text { Bus } \\
\text { No. }\end{array}$ & $\begin{array}{l}\mathrm{V} \\
\text { (Act.) }\end{array}$ & $\begin{array}{l}\text { V } \\
\text { (Con.) }\end{array}$ & $\begin{array}{l}\text { V } \\
\text { (ANN) }\end{array}$ & $\begin{array}{l}\text { Abs Error } \\
\text { (Con.) }\end{array}$ & $\begin{array}{l}\text { Abs Error } \\
\text { (ANN) }\end{array}$ \\
\hline 1 & 1.06 & 1.06 & 1.06 & 0 & 0 \\
\hline 2 & 1.0448 & 1.0427 & 1.0382 & 0.0021 & 0.0066 \\
\hline 3 & 1.01 & 1.0459 & 1.0084 & 0.0359 & 0.0016 \\
\hline 4 & 1.0138 & 1.0132 & 0.9947 & 0.0006 & 0.0191 \\
\hline 5 & 1.015 & 1.0127 & 1.0028 & 0.0023 & 0.0122 \\
\hline 6 & 1.07 & 1.0687 & 1.0698 & 0.0013 & 0.0002 \\
\hline 7 & 1.0658 & 1.0677 & 1.0157 & 0.0019 & 0.0501 \\
\hline 8 & 1.09 & 1.0907 & 1.0497 & 0.0007 & 0.0403 \\
\hline 9 & 1.0236 & 1.0443 & 1.0208 & 0.0207 & 0.0028 \\
\hline 10 & 1.0231 & 1.0316 & 1.014 & 0.0085 & 0.0091 \\
\hline 11 & 1.0419 & 1.0395 & 1.0518 & 0.0024 & 0.0099 \\
\hline 12 & 1.0527 & 1.0447 & 1.0497 & 0.008 & 0.003 \\
\hline 13 & 1.0446 & 1.0518 & 1.0417 & 0.0072 & 0.0029 \\
\hline 14 & 1.0127 & 1.1255 & 1.0154 & 0.1128 & 0.0027 \\
\hline MAE & & & & 0.0146 & 0.011464 \\
\hline Max. & & & & 0.1128 & 0.0501 \\
\hline
\end{tabular}

Table 4. Bus angle estimates for case 2

\begin{tabular}{|l|l|l|l|l|l|}
\hline $\begin{array}{l}\text { Bus } \\
\text { No. }\end{array}$ & $\begin{array}{l}\text { Angle } \\
\text { (Act.) }\end{array}$ & $\begin{array}{l}\text { Angle } \\
\text { (Con.) }\end{array}$ & $\begin{array}{l}\text { Angle } \\
\text { (ANN) }\end{array}$ & $\begin{array}{l}\text { Abs Error } \\
\text { (Con.) }\end{array}$ & $\begin{array}{l}\text { Abs Error } \\
\text { (ANN) }\end{array}$ \\
\hline 2 & -0.0888 & -0.0741 & -0.0828 & 0.0147 & 0.006 \\
\hline 3 & -0.2249 & -0.0959 & -0.1563 & 0.129 & 0.0686 \\
\hline 4 & -0.1773 & -0.1688 & -0.1933 & 0.0085 & 0.016 \\
\hline 5 & -0.1557 & -0.1554 & -0.1636 & 0.0003 & 0.0079 \\
\hline 6 & -0.2845 & -0.3194 & -0.2561 & 0.0349 & 0.0284 \\
\hline 7 & -0.1773 & -0.2082 & -0.2058 & 0.0309 & 0.0285 \\
\hline 8 & -0.1773 & -0.2209 & -0.2058 & 0.0436 & 0.0285 \\
\hline 9 & -0.3316 & -0.3727 & -0.3336 & 0.0411 & 0.002 \\
\hline 10 & -0.3279 & -0.3728 & -0.3322 & 0.0449 & 0.0043 \\
\hline 11 & -0.3083 & -0.3518 & -0.2799 & 0.0435 & 0.0284 \\
\hline 12 & -0.3021 & -0.3408 & -0.2734 & 0.0387 & 0.0287 \\
\hline 13 & -0.3052 & -0.3477 & -0.2791 & 0.0425 & 0.0261 \\
\hline 14 & -0.3399 & -0.3847 & -0.3203 & 0.0448 & 0.0196 \\
\hline MAE & & & & 0.036957 & 0.020929 \\
\hline Max & & & & 0.129 & 0.0686 \\
\hline
\end{tabular}


Table 5. Real power injection measurements and estimates (the bracketed values are actual values)

\begin{tabular}{|l|l|l|l|l|l|}
\hline $\begin{array}{l}\text { Bus } \\
\text { No. }\end{array}$ & P Meas. & $\begin{array}{l}\text { P Est. } \\
\text { (Conv) }\end{array}$ & $\begin{array}{l}\text { P Est. } \\
(\text { ANN) }\end{array}$ & $\begin{array}{l}\text { Error } \\
\text { (Con.) }\end{array}$ & $\begin{array}{l}\text { Error } \\
(\text { ANN) }\end{array}$ \\
\hline 1 & 2.3494 & 2.1243 & 2.3331 & 0.2251 & 0.0163 \\
\hline 2 & 0.141 & -0.1385 & 0.0972 & 0.2795 & 0.0438 \\
\hline 3 & $\begin{array}{l}0.9747 \\
(-0.9747)\end{array}$ & 0.3548 & -0.1824 & $0.6199^{*}$ & $1.1571^{*}$ \\
\hline 4 & -0.4583 & -0.6902 & -1.2235 & 0.2319 & 0.7652 \\
\hline 5 & -0.0709 & -0.1856 & -0.1492 & 0.1147 & 0.0783 \\
\hline 6 & -0.11 & -0.1747 & 0.0702 & 0.0647 & 0.1802 \\
\hline 7 & 0 & -0.1251 & -0.0621 & 0.1251 & 0.0621 \\
\hline 8 & 0 & -0.0835 & 0 & 0.0835 & 0 \\
\hline 9 & -0.293 & -0.4225 & -0.2854 & 0.1295 & 0.0076 \\
\hline 10 & -0.09 & -0.1658 & -0.3263 & 0.0758 & 0.2363 \\
\hline 11 & -0.0361 & -0.0912 & 0.1768 & 0.0551 & 0.2129 \\
\hline 12 & -0.0622 & -0.115 & -0.0584 & 0.0528 & 0.0038 \\
\hline 13 & -0.1265 & -0.2326 & -0.147 & 0.1061 & 0.0205 \\
\hline 14 & -0.1703 & 0.0812 & -0.0964 & 0.2515 & 0.0739 \\
\hline
\end{tabular}

Table 6. Reactive power injection measurements and estimates

\begin{tabular}{|l|l|l|l|l|l|}
\hline $\begin{array}{l}\text { Bus } \\
\text { No. }\end{array}$ & Q Meas. & $\begin{array}{l}\text { Q Est. } \\
\text { (Con) }\end{array}$ & $\begin{array}{l}\text { Q Est. } \\
\text { (ANN) }\end{array}$ & $\begin{array}{l}\text { Error } \\
\text { (Con.) }\end{array}$ & $\begin{array}{l}\text { Error } \\
\text { (ANN) }\end{array}$ \\
\hline 1 & -0.1504 & -0.0446 & 0.0368 & 0.1058 & 0.1872 \\
\hline 2 & $0(0.36463)$ & 0.0962 & 0.289 & 0.0962 & $0.289^{*}$ \\
\hline 3 & 0.0862 & 0.0354 & -0.0829 & 0.0508 & 0.1691 \\
\hline 4 & -0.0408 & -0.004 & 0.0481 & 0.0368 & 0.0889 \\
\hline 5 & -0.0183 & 0.0397 & -0.028 & 0.058 & 0.0097 \\
\hline 6 & 0.1294 & 0.0822 & 0.1418 & 0.0472 & 0.0124 \\
\hline 7 & 0 & 0.0248 & -0.2045 & 0.0248 & 0.2045 \\
\hline 8 & 0.147 & 0.1427 & 0.2023 & 0.0043 & 0.0553 \\
\hline 9 & -0.1803 & -0.3108 & -0.0783 & 0.1305 & 0.102 \\
\hline 10 & -0.0666 & -0.1276 & -0.1341 & 0.061 & 0.0675 \\
\hline 11 & -0.0188 & -0.0569 & 0.0529 & 0.0381 & 0.0717 \\
\hline 12 & -0.0166 & -0.0779 & -0.0334 & 0.0613 & 0.0168 \\
\hline 13 & -0.0642 & -0.1993 & -0.0845 & 0.1351 & 0.0203 \\
\hline 14 & -0.0514 & 0.5411 & -0.0461 & $0.5925^{*}$ & 0.0053 \\
\hline
\end{tabular}

For proposed estimator it is clear from the tables 5-8 that the maximum errors occur exactly at the same data where the gross error is present, which is not the case with conventional WLS state estimator. This is highlighted $(*)$ in Table 5 to Table 8. For case 3 a topological error was simulated as inclusion error of line 2-4. The line was actually out but the status (measurement) showed it to be in the system. WLS program was run with the line flow measurement as zero (both real and reactive), as acceptable. Results for this case are depicted in Tables 9 and 10. It is observed that the proposed estimator out performed the WLS estimator both an account of maximum error and MAE for voltage magnitude and bus angles.

Both the programs were coded in MATLAB for fair comparison. For same data set and file operations. Both programs were run on Pentium IV, Compaq Presario machine for 10 different data sets. The average time for the proposed neural network was 0.0550 seconds, whereas for WLS. State estimator it was found to be 0.8767 seconds. Time is one of the major advantages of the proposed estimator 
Table 7. Real power flow measurements and estimates

\begin{tabular}{|c|c|c|c|c|c|}
\hline LINE & P Flow Meas & $\begin{array}{l}\mathrm{P} \text { Est. } \\
\text { (Conv) }\end{array}$ & $\begin{array}{l}\text { P Est. } \\
(\text { ANN) }\end{array}$ & $\begin{array}{l}\text { Error } \\
\text { (Con.) }\end{array}$ & $\begin{array}{l}\text { Error } \\
(\mathrm{ANN})\end{array}$ \\
\hline 12 & 1.5179 & 1.3559 & 1.5233 & 0.162 & 0.0054 \\
\hline 23 & 0.7517 & 0.1103 & 0.4063 & 0.6414 & 0.3454 \\
\hline 24 & 0.5323 & 0.5707 & 0.6693 & 0.0384 & 0.137 \\
\hline 15 & 0.7992 & 0.7684 & 0.8099 & 0.0308 & 0.0107 \\
\hline 25 & 0.4432 & 0.5046 & 0.5048 & 0.0614 & 0.0616 \\
\hline 34 & -0.257 & 0.4644 & 0.2165 & 0.7214 & 0.4735 \\
\hline 45 & -0.51 & -0.2918 & -0.6908 & 0.2182 & 0.1808 \\
\hline 56 & 0.5593 & 0.752 & 0.4221 & 0.1927 & 0.1372 \\
\hline 47 & 0 & 0.2086 & 0.0621 & 0.2086 & 0.0621 \\
\hline 78 & 0 & 0.0835 & 0 & 0.0835 & 0 \\
\hline 49 & 0.2821 & 0.3975 & 0.2635 & 0.1154 & 0.0186 \\
\hline 910 & -0.0356 & 0.0527 & 0.0119 & 0.0883 & 0.0475 \\
\hline 611 & 0.17 & 0.2098 & 0.1479 & 0.0398 & 0.0221 \\
\hline 612 & 0.0883 & 0.1155 & 0.0945 & 0.0272 & 0.0062 \\
\hline 613 & 0.2409 & 0.2519 & 0.2499 & 0.011 & 0.009 \\
\hline 914 & 0.0411 & -0.0777 & -0.0337 & 0.1188 & 0.0748 \\
\hline 1011 & -0.129 & -0.1136 & -0.3146 & 0.0154 & 0.1856 \\
\hline 1213 & 0.0294 & -0.0012 & 0.0349 & 0.0306 & 0.0055 \\
\hline 1314 & 0.1203 & 0.0142 & 0.1333 & 0.1061 & 0.013 \\
\hline 21 & -1.5554 & -1.3241 & -1.4832 & 0.2313 & 0.0722 \\
\hline 32 & -0.7371 & -0.1097 & -0.3989 & 0.6274 & 0.3382 \\
\hline 42 & -0.5348 & -0.5533 & -0.6449 & 0.0185 & 0.1101 \\
\hline 51 & $0.7467(-0.747)$ & -0.7396 & -0.7774 & $1.4863^{*}$ & $1.5241^{*}$ \\
\hline 52 & -0.408 & -0.4912 & -0.4911 & 0.0832 & 0.0831 \\
\hline 43 & 0.2561 & -0.4512 & -0.2134 & 0.7073 & 0.4695 \\
\hline 54 & 0.4644 & 0.2931 & 0.6972 & 0.1713 & 0.2328 \\
\hline 65 & -0.6321 & -0.752 & -0.4221 & 0.1199 & 0.21 \\
\hline 74 & 0 & -0.2086 & -0.0621 & 0.2086 & 0.0621 \\
\hline 87 & 0 & -0.0835 & 0 & 0.0835 & 0 \\
\hline 94 & -0.3218 & -0.3975 & -0.2635 & 0.0757 & 0.0583 \\
\hline 109 & 0.0388 & -0.0521 & -0.0117 & 0.0909 & 0.0505 \\
\hline 116 & -0.1703 & -0.2059 & -0.146 & 0.0356 & 0.0243 \\
\hline 126 & -0.0938 & -0.1138 & -0.0934 & 0.02 & 0.0004 \\
\hline 136 & -0.2144 & -0.2482 & -0.2456 & 0.0338 & 0.0312 \\
\hline 149 & -0.0423 & 0.0873 & 0.034 & 0.1296 & 0.0763 \\
\hline 1110 & 0.1306 & 0.1146 & 0.3228 & 0.016 & 0.1922 \\
\hline 1312 & -0.0277 & 0.0014 & -0.0347 & 0.0291 & 0.007 \\
\hline 1413 & -0.1169 & -0.0061 & -0.1304 & 0.1108 & 0.0135 \\
\hline
\end{tabular}


Table 8. Reactive power flow measurements and estimates

\begin{tabular}{|ll|l|l|l|l|l|}
\hline LINE & $\begin{array}{l}\text { Q Flow } \\
\text { Meas }\end{array}$ & $\begin{array}{l}\text { Q Est. } \\
\text { (Con) }\end{array}$ & $\begin{array}{l}\text { Q Est. } \\
\text { (ANN) }\end{array}$ & $\begin{array}{l}\text { Error } \\
\text { (Con.) }\end{array}$ & $\begin{array}{l}\text { Error } \\
\text { (ANN) }\end{array}$ \\
\hline 1 & 2 & -0.1922 & -0.1134 & -0.075 & 0.0788 & 0.1172 \\
\hline 2 & 3 & 0.0345 & -0.0653 & 0.0507 & 0.0998 & 0.0162 \\
\hline 2 & 4 & 0.0092 & -0.007 & 0.0513 & 0.0162 & 0.0421 \\
\hline 1 & 5 & 0.0604 & 0.0688 & 0.1118 & 0.0084 & 0.0514 \\
\hline 2 & 5 & 0.0366 & 0.0162 & 0.0477 & 0.0204 & 0.0111 \\
\hline 3 & 4 & 0.0697 & 0.0154 & -0.0176 & 0.0543 & 0.0873 \\
\hline 4 & 5 & 0.1273 & 0.0994 & 0.0327 & 0.0279 & 0.0946 \\
\hline 5 & 6 & 0.1551 & 0.1621 & 0.0685 & 0.007 & 0.0866 \\
\hline 4 & 7 & -0.139 & -0.1506 & 0.0095 & 0.0116 & 0.1485 \\
\hline 7 & 8 & -0.0141 & -0.1386 & -0.1958 & 0.1245 & 0.1817 \\
\hline & $-0.141)$ & & & & \\
\hline 4 & 9 & 0.0669 & 0.045 & 0.031 & 0.0219 & 0.0359 \\
\hline 9 & 10 & 0.0205 & 0.137 & 0.0771 & 0.1165 & 0.0566 \\
\hline 6 & 11 & 0.0714 & 0.0598 & 0.0277 & 0.0116 & 0.0437 \\
\hline 6 & 12 & 0.03 & 0.0459 & 0.0391 & 0.0159 & 0.0091 \\
\hline 6 & 13 & 0.0895 & 0.0147 & 0.1057 & 0.0748 & 0.0162 \\
\hline 9 & 14 & 0.0222 & -0.2768 & 0.0365 & 0.299 & 0.0143 \\
\hline 10 & 11 & -0.0463 & 0.0077 & -0.0575 & 0.054 & 0.0112 \\
\hline 12 & 13 & 0.011 & -0.0355 & 0.0034 & 0.0465 & 0.0076 \\
\hline 13 & 14 & 0.0377 & -0.2276 & 0.016 & 0.2653 & 0.0217 \\
\hline 2 & 1 & 0.3016 & 0.1522 & 0.1392 & 0.1494 & 0.1624 \\
\hline 3 & 2 & 0.0181 & 0.02 & -0.0653 & 0.0019 & 0.0834 \\
\hline 4 & 2 & -0.0016 & 0.0203 & -0.0159 & 0.0219 & 0.0143 \\
\hline 5 & 1 & 0.0065 & -0.0026 & -0.0301 & 0.0091 & 0.0366 \\
\hline 5 & 2 & -0.0414 & -0.0112 & -0.0413 & 0.0302 & $1 \mathrm{E}-04$ \\
\hline 4 & 3 & -0.0871 & -0.0182 & -0.0092 & 0.0689 & 0.0779 \\
\hline 5 & 4 & -0.1305 & -0.1086 & -0.0251 & 0.0219 & 0.1054 \\
\hline 6 & 5 & -0.0442 & -0.0382 & -0.0307 & 0.006 & 0.0135 \\
\hline 7 & 4 & 0.1556 & 0.1634 & -0.0088 & 0.0078 & 0.1644 \\
\hline 8 & 7 & 0.1517 & 0.1427 & 0.2023 & 0.009 & 0.0506 \\
\hline 9 & 4 & -0.0189 & 0.0363 & 0.006 & 0.0552 & 0.0249 \\
\hline 10 & 9 & -0.019 & -0.1353 & -0.0766 & 0.1163 & 0.0576 \\
\hline 11 & 6 & -0.0613 & -0.0515 & -0.0238 & 0.0098 & 0.0375 \\
\hline 12 & 6 & -0.0282 & -0.0424 & -0.0368 & 0.0142 & 0.0086 \\
\hline 13 & 6 & -0.0869 & -0.0074 & -0.0973 & 0.0795 & 0.0104 \\
\hline 14 & 9 & -0.0217 & 0.2972 & -0.0359 & $0.3189 *$ & 0.0142 \\
\hline 11 & 10 & 0.0483 & -0.0053 & 0.0766 & 0.0536 & 0.0283 \\
\hline 13 & 12 & -0.0107 & 0.0357 & -0.0032 & 0.0464 & 0.0075 \\
\hline 14 & 13 & -0.0302 & 0.2439 & -0.0103 & 0.2741 & 0.0199 \\
\hline & & & & & \\
\hline
\end{tabular}


Table 9. Voltage estimates for case 3

\begin{tabular}{|l|l|l|l|l|l|}
\hline $\begin{array}{l}\text { BUS } \\
\text { No. }\end{array}$ & $\begin{array}{l}\text { V } \\
\text { (Act.) }\end{array}$ & $\begin{array}{l}\text { V } \\
\text { (Con.) }\end{array}$ & $\begin{array}{l}\text { V } \\
\text { (ANN) }\end{array}$ & $\begin{array}{l}\text { Abs } \\
\text { Error } \\
\text { (Con.) }\end{array}$ & $\begin{array}{l}\text { Abs } \\
\text { Error } \\
\text { (ANN) }\end{array}$ \\
\hline 1 & 1.06 & 1.06 & 1.06 & 0 & 0 \\
\hline 2 & 1.045 & 1.0428 & 1.0443 & 0.0022 & 0.0007 \\
\hline 3 & 1.01 & 1.0136 & 1.0092 & 0.0036 & 0.0008 \\
\hline 4 & 1.0019 & 1.0137 & 1.0103 & 0.0118 & 0.0084 \\
\hline 5 & 1.0073 & 1.0171 & 1.0142 & 0.0098 & 0.0069 \\
\hline 6 & 1.07 & 1.0776 & 1.0699 & 0.0076 & $1 \mathrm{E}-04$ \\
\hline 7 & 1.0532 & 1.0613 & 1.058 & 0.0081 & 0.0048 \\
\hline 8 & 1.09 & 1.0976 & 1.0928 & 0.0076 & 0.0028 \\
\hline 9 & 1.0461 & 1.0536 & 1.0517 & 0.0075 & 0.0056 \\
\hline 10 & 1.0426 & 1.0497 & 1.0459 & 0.0071 & 0.0033 \\
\hline 11 & 1.0525 & 1.0597 & 1.0576 & 0.0072 & 0.0051 \\
\hline 12 & 1.0538 & 1.0614 & 1.0557 & 0.0076 & 0.0019 \\
\hline 13 & 1.0484 & 1.0559 & 1.0493 & 0.0075 & 0.0009 \\
\hline 14 & 1.0271 & 1.0331 & 1.0328 & 0.006 & 0.0057 \\
\hline MAE & & & & 0.006686 & 0.003357 \\
\hline Max & & & & 0.0118 & 0.0084 \\
\hline
\end{tabular}

Table 10. Bus angle estimates for case 3

\begin{tabular}{|l|l|l|l|l|l|}
\hline $\begin{array}{l}\text { BUS } \\
\text { No. }\end{array}$ & $\begin{array}{l}\text { Angle } \\
\text { (Act.) }\end{array}$ & $\begin{array}{l}\text { Angle } \\
\text { (Con.) }\end{array}$ & $\begin{array}{l}\text { Angle } \\
(\text { ANN) }\end{array}$ & $\begin{array}{l}\text { Abs } \\
\text { Error } \\
\text { (Con.) }\end{array}$ & $\begin{array}{l}\text { Abs } \\
\text { Error } \\
\text { (ANN) }\end{array}$ \\
\hline 1 & 0 & 0 & 0 & 0 & 0 \\
\hline 2 & -0.0824 & -0.0903 & -0.0832 & 0.0079 & 0.0008 \\
\hline 3 & -0.2588 & -0.2362 & -0.2347 & 0.0226 & 0.0241 \\
\hline 4 & -0.2377 & -0.1876 & -0.1908 & 0.0501 & 0.0469 \\
\hline 5 & -0.1932 & -0.1578 & -0.1665 & 0.0354 & 0.0267 \\
\hline 6 & -0.2959 & -0.2522 & -0.2601 & 0.0437 & 0.0358 \\
\hline 7 & -0.287 & -0.2423 & -0.2442 & 0.0447 & 0.0428 \\
\hline 8 & -0.287 & -0.2438 & -0.2442 & 0.0432 & 0.0428 \\
\hline 9 & -0.3124 & -0.2681 & -0.2769 & 0.0443 & 0.0355 \\
\hline 10 & -0.3144 & -0.2701 & -0.2806 & 0.0443 & 0.0338 \\
\hline 11 & -0.3075 & -0.263 & -0.2688 & 0.0445 & 0.0387 \\
\hline 12 & -0.3111 & -0.2654 & -0.2745 & 0.0457 & 0.0366 \\
\hline 13 & -0.3123 & -0.2669 & -0.277 & 0.0454 & 0.0353 \\
\hline 14 & -0.331 & -0.2863 & -0.2939 & 0.0447 & 0.0371 \\
\hline MAE & & & & 0.036893 & 0.031207 \\
\hline Max. & & & & 0.0501 & 0.0469 \\
\hline
\end{tabular}

\section{Conclusion}

Radial Basis Function neural network is designed and tested for IEEE 14-bus system. The performance of the proposed neural network estimator is compared with conventional WLSE on basis of time and accuracy. The time taken by the RBF estimator was very less, compared to its conventional counterpart. It is shown that for gross error and topological error present in the measurement data, the proposed RBF state estimator was more accurate as compared to WLSE. The bad data analysis shows that the gross errors can easily be detected in case of RBF estimator as there is no data smearing as in case of conventional WLSE. However, WLSE method was superior in cases where the gross is not present in the measurements. However, state estimates obtained by the RBF estimator were accurate for practical purposes. 


\section{References}

Demuth Howard, Beale Mark, 1992, Neural Networks Toolbox, The Mathworks Inc.

Garcia A., Monticelli A., and Abreu P., 1979, Fast decoupled static state estimation and data processing, IEEE Transactions, PAS, vol. 98, No. 5, pp. 1645-1652.

Horisberger H.P., Richard J.C. and Rossier C., 1976, A fast decoupled static state estimator for electric power system, IEEE

Transactions, PAS, vol. 95, issue 1, pp. 208-215

Monticelli A., 2000, Electric power system state estimation, Proc. IEEE, vol. 88, No.2, pp.262-282.

Singh D. and Singh S.P., 2001, A self selecting neural network for short-term load forecasting, Journal of Electric Power Components and Systems, No. 29, pp.117- 130.

Wallach Y., 1986, Calculations and Programs for Power System Networks, New Jersy, Prentice -Hall Inc., pp. 40-41.

Wu F.F., 1990, Power system state estimation: A survey, Elect. Power Eng. Syst. Vol. 12, pp. 80-87.

Biographical notes:

Dr. J.P. Pandey received his BTech and MTech degree in Electrical Engineering from Kamala Nehru Institute of Technology Sultanpur (UP), India. He obtained his PhD degree from UP Technical University, Lucknow, India. Presently he is professor in the department of electrical engineering at KNIT Sultanpur. His research interests include applications of artificial techniques to electrical engineering problems and power system.

Dr. D. Singh received his Ph.D. degree from Institute of Technology (IT), BHU, India. He is working as Associate Professor at IT BHU, India. His research interests include applications of artificial techniques to electrical engineering problems and power system.

Received September 2009

Accepted March 2010

Final acceptance in revised form March 2010 